\title{
Prevalence of metabolic syndrome in patients with schizophrenia, and metabolic changes after 3 months of treatment with antipsychotics - results from a German observational study
}

\author{
Susanne Kraemer ${ }^{1 *}$, Anette Minarzyk ${ }^{1}$, Thomas Forst ${ }^{2}$, Daniel Kopf ${ }^{3}$ and Hans-Peter Hundemer ${ }^{1}$
}

\begin{abstract}
Background: This observational study explored the prevalence of metabolic syndrome (MetS) in adult in- and outpatients with untreated or treated schizophrenia at baseline, and month-3 after initiation or switch of antipsychotic treatment.

Methods: MetS-prevalence (AHA/NHLB-definition) was assessed and Clopper-Pearson 95\% confidence intervals (Cls) were calculated. Factors associated with MetS were explored through univariate and multivariate logistic regressions (both visits).

Results: MetS-prevalence was $44.3 \%(\mathrm{Cl} 39.8 ; 48.9)$ at baseline and $49.6 \%(\mathrm{Cl} 45.0 ; 54.2)$ at month-3. Previously unmedicated patients showed the lowest baseline MetS-prevalence $(24.7 \%, \mathrm{Cl} 18.3 ; 32.1)$. MetS-prevalence was not significantly different, regardless if patients previously received typical or atypical antipsychotics. Increased MetS-risk was associated with somatic comorbidity and non-smoking at both visits, and with non-psychiatric co-medication, male sex, and increased C-reactive protein at month-3.
\end{abstract}

Conclusions: At baseline, MetS was most prevalent in patients with previous antipsychotic medication. Limited metabolic changes were observed 3 months after switch/initiation of antipsychotic therapy.

Trial Registration Number: ClinicalTrials.gov Identifier: n.a.

\section{Background}

Several studies have reported increased mortality in patients with schizophrenia. Besides higher risks for cancer, respiratory and cerebrovascular disorders, and of death from suicide or homicide, the main cause is cardiovascular disease [1-7]. Even before antipsychotic medication became available in the 1950s, abnormal responses to insulin and diabetes-like glucose tolerance curves $[8,9]$ were observed in psychiatric patients. Planansky and Heilizer [10] reported weight gain already in 1959 in patients treated with chlorpromazine. Thakore et al. [11] found higher BMI (body mass index), WHR (waist/hip ratio), and a threefold amount of intra-

\footnotetext{
* Correspondence: kraemer_susanne@lilly.com

'Lilly Deutschland GmbH, Medical Department, 61352 Bad Homburg, Werner -Reimers-Str. 2-4, Germany

Full list of author information is available at the end of the article
}

abdominal fat (IAF) in untreated schizophrenia patients compared to healthy controls. Further factors associated with schizophrenia, like unhealthy diet patterns [12], smoking [13], lower levels of physical activity and cardiorespiratory fitness [14], and poor living conditions certainly contribute to the finding that these patients, including those on antipsychotics, may have a higher risk to develop metabolic syndrome (MetS) than the general population $[1,15,16]$. It has been suggested that changes in metabolic parameters in patients treated with antipsychotics may, in part, be genetically determined [17].

MetS is characterized by the coincidence of hypertension, abdominal obesity, impaired lipid metabolism (blood triglycerides, cholesterol) and/or impaired blood glucose regulation. Though the concept of MetS is universally accepted, there is still controversy on the exact 
pathophysiology, resulting in differing definitions (e.g. by the American Heart Association [18], the National Cholesterol Education Program [19], and the International Diabetes Federation/Word Health Organization [20]).

Nevertheless has the awareness of schizophrenia patients' risk to develop MetS resulted in treatment guidelines which demand the regular monitoring of relevant physical and laboratory parameters; in several countries these are meanwhile regarded clinical standard of care [21,22].

Few data are available so far on the prevalence of MetS in schizophrenia patients in Germany. In our observational study we addressed this gap, assessing the prevalence of MetS at baseline and month-3 of treatment with different antipsychotic medications as well as possible predictors for the development of MetS.

\section{Methods Study design}

This was a prospective, 3-month, multi-center, diseaseoriented, observational study conducted in Germany from September 2006 to April 2008. Eligible were inand outpatients ( $\geq 18$ years) diagnosed with schizophrenia according to ICD-10 criteria, who either entered the study untreated and were initiated on antipsychotic therapy, or were on antipsychotic treatment and needed to be switched to a new primary medication (initiation/ change of medication at baseline). Additionally, routine blood samples had to be scheduled for these patients at baseline and month- 3 irrespective of the study. Due to the observational design, no further clinical in- or exclusion criteria were specified, treatment decisions were entirely left to the discretion of investigators and patients.

The study was approved by the responsible ethical review board. Written informed consent for the release of medical data was obtained from all patients according to local regulations. As the German Society of Psychiatry, Psychotherapy and Neurology [21] recommends metabolic screening for all patients with schizophrenia, referring to the Consensus Statement of the American Diabetes Association [23], blood tests are considered standard of care in schizophrenia treatment in Germany. Therefore the ethical review board consented that drawing blood samples did not interfere with the observational design of the study.

Our primary research objective was to assess the prevalence of MetS, as defined by the National Cholesterol Education Program, Adult Treatment Panel III in 2001 (NCEP-ATP III) [19] and the American Heart Association/National Heart, Lung and Blood Institute in 2005 (AHA/NHLB) [18], in a German cohort of patients with schizophrenia. The details of both definitions are given in Table 1. As a secondary outcome, we compared MetS-prevalence at baseline and after three months of treatment with the newly prescribed antipsychotic. A further objective was the detection of predictors for the development of the MetS.

Patients were documented at baseline and at month-3. At baseline, patient demographics and characteristics were recorded. At both visits, vital and physical parameters were collected, and fasting blood samples were drawn and analyzed. Apart from the blood levels of high-density lipoprotein (HDL) cholesterol, triglycerides, and glucose, which were needed to diagnose MetS, we determined C-reactive protein (CRP) $[24,25]$ ) as an additional indicator of cardiovascular risk, and $\mathrm{HbA}_{1 \mathrm{c}}$ (glycated hemoglobin), to assess long term glucose regulation [26].

Blood samples were analyzed in a central laboratory, which applied test reference ranges (i.e. normal ranges) as per Table 2 .

For assessment of disease severity, the Clinical Global Impression - Severity scale (CGI-S), which rates the severity of the patient's illness on a 7 -point scale $(1=$ normal to 7 = extremely ill) was used at both visits [27].

\section{Sample size considerations and statistical analysis}

The sample size was designed to reach $2.5 \%$ precision for the estimate of MetS prevalence rate - i.e. the $95 \%$ confidence interval bounds within estimated rate $\pm 2.5 \%$ $\left(1.96 x \sqrt{\frac{\hat{p}(1-\hat{p})}{n}}=0.025\right)$ - and assuming a prevalence rate around $41 \%$, based on results of the CATIE study [28]. This yielded a first estimate of 1486 patients, further adjusted accounting for $25 \%$ of drop outs. We finally aimed to enroll 1900 patients.

Statistical analyses were performed on two sets: (a) the full analysis set (FAS), including all patients meeting the entry criteria, and (b) the complete metabolic data set (CMD), comprising all patients with a full set of metabolic data for both visits, who did not change their antipsychotic treatment during the course of the study.

Primary analyses were conducted on the FAS, with subgroups formed according to the antipsychotic treatment they received within 6 months prior to baseline (Prev-AP = previous antipsychotic treatment cohorts).

The evaluations of the secondary outcomes were performed on the CMD-set, with subgroups formed according to the treatment patients received after baseline (New-AP = new antipsychotic treatment cohorts). In both sets, compounds which were less frequently prescribed had to be grouped to reach large enough cohorts for reasonable statistical evaluation.

Patient demographics and characteristics, physical, vital and laboratory parameters were described by 
Table 1 Definitions and reference ranges for metabolic syndrome according to NCEP-ATP III and AHA/NHLB

\begin{tabular}{|c|c|c|}
\hline Risk factor & Defining measure NCEP-ATP III & Defining measure AHA/NHLB \\
\hline \multicolumn{3}{|c|}{$\begin{array}{l}\text { Abdominal obesity } \\
\text { (waist circumference) }\end{array}$} \\
\hline Men & $>102 \mathrm{~cm}$ & $\geq 102 \mathrm{~cm}$ \\
\hline Women & $>88 \mathrm{~cm}$ & $\geq 88 \mathrm{~cm}$ \\
\hline Triglycerides & $\geq 150 \mathrm{mg} / \mathrm{dL}$ & $\geq 150 \mathrm{mg} / \mathrm{dL}$ or on drug treatment for elevated triglycerides \\
\hline \multicolumn{3}{|c|}{ High density lipoprotein (HDL) } \\
\hline Men & $<40 \mathrm{mg} / \mathrm{dL}$ & $<40 \mathrm{mg} / \mathrm{dL}$ or on drug treatment for reduced $\mathrm{HDL}$-cholesterol \\
\hline Women & $<50 \mathrm{mg} / \mathrm{dL}$ & $<50 \mathrm{mg} / \mathrm{dL}$ or on drug treatment for reduced $\mathrm{HDL}$-cholesterol \\
\hline Blood pressure & Systolic $\geq 130$ or diastolic $\geq 85 \mathrm{mmHg}$ & Systolic $\geq 130$ or diastolic $\geq 85 \mathrm{mmHg}$ or on antihypertensive medication \\
\hline Fasting glucose & $\geq 110 \mathrm{mg} / \mathrm{dL}$ & $\geq 100 \mathrm{mg} / \mathrm{dL}$ or on antidiabetic medication \\
\hline
\end{tabular}

Abbreviations: AHA/NHLB = American Heart Association/National Heart, Lung and Blood Institute; NCEP-ATP III = National Cholesterol Education Program, Adult Treatment Panel 3rd report

According to both definitions, a diagnosis of metabolic syndrome is established if at least three of the above risk factors are present.

standard summary statistics and used to determine the presence of MetS at baseline and at month-3.

Clopper-Pearson exact 95\% confidence intervals (CI) relating to MetS prevalence were calculated for both sets of antipsychotic treatment cohorts (Prev-AP, FAS, and New-AP, CMD-Set).

The association between the presence of MetS and possible risk factors for its development was analyzed for each visit separately, through univariate and multivariable forward selection logistic models (CMD-set). Candidate covariates entered in the forward selection process were not pre-screened based on the results of univariate analyses, all of them were considered. The significance level (chi-square score test) for the forward selection process was set to $\leq 0.1$. No interaction was considered. Odds Ratios (OR) were estimated together with their asymptotic Wald 95\% confidence interval. For continuous factors ORs relate to an increase by 1 unit. Tested covariates (both visits) included: age, sex, time since first symptoms, any concomitant somatic diseases (yes/no), any concomitant non-psychiatric medication at baseline (yes/no), PrevAP cohort (reference category: Prev-None), active smoker (yes/no), CGI-S score at baseline, CRP $\geq 3 \mathrm{mg} / \mathrm{L}$ (yes/no), and $\mathrm{HbA}_{1 \mathrm{c}} \geq 6.5 \%$ (yes/no).

Table 2 Test reference ranges applied for blood samples

\begin{tabular}{ll}
\hline Parameter & Range \\
\hline $\mathrm{HbA}_{1 \mathrm{c}}(\%)$ & 4 to 6 \\
Triglycerides $(\mathrm{mg} / \mathrm{dL})$ & 9 to 150 \\
$\mathrm{HDL}$ - Cholesterol $(\mathrm{mg} / \mathrm{dL})$ & 40 to 150 \\
Glucose $(\mathrm{mg} / \mathrm{dL})$ & 70 to 115 \\
CRP $(\mathrm{mg} / \mathrm{L})$ & 0 to 3 \\
\hline
\end{tabular}

Abbreviations: $\mathrm{HDL}=$ High density lipoprotein; $\mathrm{CRP}$ = C-reactive protein, $\mathrm{HbA}_{1 \mathrm{c}}=$ glycated hemoglobin .

\section{Results}

Patient disposition and baseline characteristics

Only 718 patients could be documented at 162 investigational sites within the recruitment period. Figure 1 displays the details of patient disposition.

Table 3 shows the distribution of patients in the treatment cohorts.

The age ranged between 18 and 86 years, with upper and lower quartiles of 36 and 54 years. Women had a

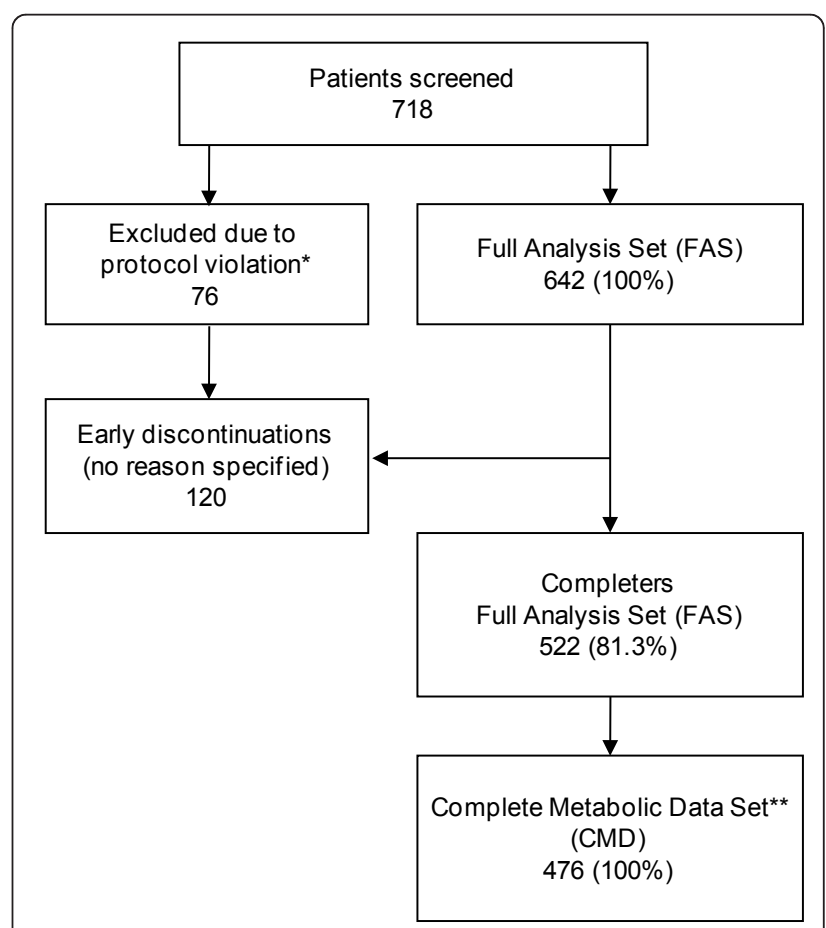

Figure 1 Patient disposition. * Time span between baseline visit and blood draw $>3$ weeks. ${ }^{* *}$ Patients with complete metabolic data sets for both visits, who did not change antipsychotic treatment during the course of the study. 
Table 3 Patient distribution in treatment cohorts, Prev-AP FAS and New-AP CMD-set

\begin{tabular}{|c|c|c|}
\hline $\begin{array}{l}\text { Cohorts Prev-AP, FAS }(\mathrm{N}= \\
642)\end{array}$ & & $\mathrm{N}(\%)$ \\
\hline Prev-Olz & previous olanzapine monotherapy & $62(9.7 \%)$ \\
\hline Prev-Risp & previous risperidone monotherapy & $67(10.4 \%)$ \\
\hline Prev-Quet & previous quetiapine monotherapy & $49(7.6 \%)$ \\
\hline Prev-Atyp & $\begin{array}{l}\text { previous other atypical antipsychotic monotherapy (amisulpride, aripiprazoleclozapine, ziprasidone, } \\
\text { paliperidone) }\end{array}$ & $\begin{array}{r}103 \\
(16.0 \%)\end{array}$ \\
\hline Prev-Typ & previous typical antipsychotics & $90(14.0 \%)$ \\
\hline Prev-Comb & any previous combination therapy & $\begin{array}{r}109 \\
(17.0 \%)\end{array}$ \\
\hline Prev-None & not treated with antipsychotics within6 months prior to study entry & $\begin{array}{r}162 \\
(25.2 \%)\end{array}$ \\
\hline $\begin{array}{l}\text { Cohorts New-AP, CMD-set }(\mathrm{N}= \\
\text { 476) }\end{array}$ & & N (\%) \\
\hline New-Olz & new olanzapine monotherapy & $\begin{array}{r}206 \\
(43.3 \%)\end{array}$ \\
\hline New-Risp & new risperidone monotherapy & $69(14.5 \%)$ \\
\hline New-Quet & new quetiapine monotherapy & $33(6.9 \%)$ \\
\hline New-Atyp & $\begin{array}{l}\text { new other atypical antipsychotic monotherapy (amisulpride, aripiprazoleclozapine, ziprasidone, } \\
\text { paliperidone) }\end{array}$ & $72(15.1 \%)$ \\
\hline New-Typ & new typical antipsychotic & $16(3.4 \%)$ \\
\hline New-Comb & new combination therapy (any combination) & $80(16.8 \%)$ \\
\hline
\end{tabular}

Abbreviations: CMD = complete metabolic data; FAS = full analysis set; New-AP = new antipsychotic treatment cohort; Prev-AP = previous antipsychotic treatment cohort;

mean age of $47.3 \pm 13.1$ years, for men it was $43.1 \pm 13.1$ years. A mean waist circumference of $103.5 \pm 16.0 \mathrm{~cm}$ for men, and $95.6 \pm 17.5 \mathrm{~cm}$ for women indicated overweight in a considerable proportion of patients. Prev-None was the only cohort with a mean BMI near to normal range $\left(25.3 \mathrm{~kg} / \mathrm{m}^{2}\right)$. The mean time since first diagnosis was 9 years, ranging from 0 to 51 years. Baseline characteristics in the overall CMD-set resembled those observed in the FAS. For details on demographics and baseline characteristics of both sets of treatment cohorts, see Table 4 and Table 5.

In the Prev-None cohort $28.4 \%$ of the patients reported any concomitant disease (Table 6), whereas the previously treated patients had rates between $29.9 \%$ (Pre-Risp) and 41.7\% (Pre-Comb). Non-psychiatric comedication was taken by approximately $20 \%$ of the patients, mostly antihypertensives (Table 7 ).

Table 8 shows the proportions of patients (FAS) with blood test values out of the reference range at baseline. Within the Prev-AP cohorts, the percentages for PrevNone were at the lower end for all parameters.

\section{MetS at Baseline}

For both MetS definitions, NCEP-ATP III and AHA/ NHLB, the differences between the cohorts with previous antipsychotic treatment were not statistically significant (Table 9). However, the Prev-None cohort had a significantly lower prevalence of MetS compared to any other Prev-AP cohort according to both definitions, except Pre-Risp (difference not significant).

\section{Development of MetS between baseline and endpoint at month-3}

In the following, we report results for MetS according to AHA/NHLB-definition only, as both definitions are largely based on the same parameters; only the AHA/ NHLB-definition additionally includes the treatment with antihypertensives, antidiabetics and lipid lowering drugs and was therefore regarded the more sensitive instrument.

At baseline, New-Typ had a significantly higher prevalence than New-Olz and New-Risp, but not compared to the other New-AP cohorts (differences lacked significance, see CIs in Table 10). At month-3 the MetS prevalence had increased from $44.3 \%$ to $49.6 \%$; however, this change was not significant (95\% CIs overlapping substantially). Comparing the New-AP cohorts, observed changes included minor changes, but none of these were statistically significant (Table 10).

Table 11 provides an overview on the change of the particular MetS-factors. Large standard deviations indicate a great variability of individual change in both directions. Looking at the median, however, little to no change was observed in waist-circumference, blood pressure, CRP, and $\mathrm{HbA}_{1 \mathrm{c}}$. There was an increase in median glucose values in all cohorts but New-Risp, and 
Table 4 Patient Demographics and Baseline Characteristics (Prev-AP cohorts)

\begin{tabular}{|c|c|c|c|c|c|c|c|c|c|c|}
\hline Prev-AP*, FAS & & Age (years) & BMI $\left(\mathrm{kg} / \mathrm{m}^{2}\right)$ & Waist $(\mathrm{cm})$ & $\mathrm{SBP}(\mathrm{mm} / \mathrm{Hg})$ & $\mathrm{DBP}(\mathrm{mm} / \mathrm{Hg})$ & CGI-S score & & Male & Smokers \\
\hline Prev-Olz & Mean & 42.9 & 28.9 & 103.4 & 131.1 & 83.6 & 3.5 & $N$ & 36 & 26 \\
\hline$(\mathrm{N}=62)$ & $\mathrm{SD}$ & 13.9 & 5.2 & 17.1 & 18.0 & 8.2 & 1.2 & $\%$ & 58.1 & 41.9 \\
\hline Prev-Risp & Mean & 46.0 & 28.9 & 103.4 & 128.2 & 83.1 & 4.1 & N & 38 & 30 \\
\hline$(N=67)$ & SD & 13.2 & 6.2 & 17.3 & 12.7 & 7.4 & 1.2 & $\%$ & 56.7 & 44.8 \\
\hline Prev-Quet & Mean & 46.2 & 27.0 & 100.0 & 125.9 & 81.7 & 3.9 & N & 24 & 17 \\
\hline$(N=49)$ & SD & 12.1 & 4.9 & 18.2 & 13.5 & 8.5 & 1.2 & $\%$ & 49.0 & 34.7 \\
\hline Prev-Atyp & Mean & 46.7 & 28.4 & 101.1 & 128.1 & 81.9 & 4.0 & $\mathrm{~N}$ & 50 & 43 \\
\hline$(N=103)$ & SD & 13.2 & 5.8 & 17.2 & 16.7 & 9.9 & 1.2 & $\%$ & 48.5 & 41.8 \\
\hline Prev-Typ & Mean & 49.1 & 28.4 & 102.1 & 129.3 & 84.0 & 4.0 & N & 42 & 43 \\
\hline$(N=90)$ & SD & 11.9 & 5.9 & 18.7 & 15.9 & 9.7 & 1.2 & $\%$ & 46.7 & 47.8 \\
\hline Prev-Com & Mean & 44.5 & 29.3 & 103.3 & 127.0 & 82.3 & 3.6 & $N$ & 58 & 43 \\
\hline$(\mathrm{N}=109)$ & SD & 11.6 & 5.4 & 14.7 & 11.3 & 8.9 & 1.2 & $\%$ & 53.2 & 39.5 \\
\hline Prev-None & Mean & 43.0 & 25.3 & 91.3 & 125.0 & 80.2 & 4.2 & $N$ & 69 & 61 \\
\hline$(N=162)$ & SD & 14.7 & 4.5 & 15.1 & 15.7 & 9.3 & 1.0 & $\%$ & 42.6 & 37.7 \\
\hline Total FAS & Mean & 45.2 & 27.8 & 99.5 & 127.4 & 82.1 & 3.9 & $\mathrm{~N}$ & 317 & 263 \\
\hline$(\mathrm{N}=642)$ & SD & 13.3 & 5.6 & 17.2 & 15.1 & 9.1 & 1.2 & $\%$ & 49.4 & 41.0 \\
\hline
\end{tabular}

Abbreviations: $\mathrm{BMI}=$ body mass index; $\mathrm{CGI}-\mathrm{S}=$ clinical global impression - severity scale; DBP = diastolic blood pressure; FAS = full analysis set; Prev-AP = previous antipsychotic treatment cohort; SBP = systolic blood pressure; SD = standard deviation, Waist = waist circumference

Missing values: BMI 1 (Prev-Comb), waist circumference 1 (Prev-Comb), SBP and DBP 1 (Prev-Risp)

* The time period through which the previous antipsychotic medication had been taken ranged from less than a month up to more than a decade.

also in triglycerides with exception of the New-Typ and New-Comb. A decrease in the median HDL-cholesterol values was observed in all cohorts.

\section{Factors associated with MetS (NCEP-ATP III -definition)}

Factors found significantly associated with the presence of MetS in the multivariate logistic regression (CMD) were concomitant somatic disease (adjusted OR 4.09, p $<0.0001$ ) and non-smoking (smoking vs. not, adjusted OR 0.53, $p=0.0098)$ at baseline. The same was observed at month-3, with an adjusted OR of 0.60 ( $\mathrm{p}=$ 0.049) for smoking versus non-smoking, and a still negative, though not significant, effect of having any concomitant somatic disease (adjusted OR 1.83, $\mathrm{p}=$ 0.0796). Other factors associated with MetS at month-3 included male sex (female vs. male, OR 0.56, $\mathrm{p}=$ 0.0185), having a CRP $\geq 3 \mathrm{mg} / \mathrm{L}$ (adjusted OR of $2.00, \mathrm{p}$ $=0.006)$, and receiving non-psychiatric concomitant medication (adjusted OR of $1.98, p=0.059$ ). In the baseline multivariate model the factors $C R P \geq 3 \mathrm{mg} / \mathrm{L}$ and concomitant non-psychiatric medication were eliminated during the multivariable forward selection process, though they showed significance in the univariate logistic regressions $(\mathrm{CRP} \geq 3 \mathrm{mg} / \mathrm{L}$ unadjusted $\mathrm{OR}$ of 1.68

Table 5 Patient Demographics and Baseline Characteristics (New-AP cohorts)

\begin{tabular}{|c|c|c|c|c|c|c|c|c|c|c|}
\hline New-AP, CMD-set & & Age (years) & BMI $\left(\mathrm{kg} / \mathrm{m}^{2}\right)$ & Waist $(\mathrm{cm})$ & $\mathrm{SBP}(\mathrm{mm} / \mathrm{Hg})$ & $\mathrm{DBP}(\mathrm{mm} / \mathrm{Hg})$ & CGI-S score & & Male & Smokers \\
\hline New-Olz & Mean & 46.3 & 26.6 & 96.8 & 126.3 & 81.6 & 4.1 & $N$ & 106 & 86 \\
\hline$(N=206)$ & SD & 13.5 & 4.7 & 17.2 & 15.2 & 8.8 & 1.2 & $\%$ & 51.5 & 41.8 \\
\hline New-Risp & Mean & 45.6 & 27.5 & 98.1 & 128.4 & 81.0 & 4.1 & $\mathrm{~N}$ & 30 & 23 \\
\hline$(\mathrm{N}=69)$ & SD & 11.6 & 5.6 & 15.9 & 14.0 & 8.8 & 0.9 & $\%$ & 43.5 & 33.3 \\
\hline New-Quet & Mean & 48.5 & 28.6 & 100.7 & 125.6 & 82.5 & 3.5 & $\mathrm{~N}$ & 11 & 13 \\
\hline$(N=33)$ & SD & 14.2 & 4.7 & 13.5 & 11.4 & 7.1 & 1.3 & $\%$ & 33.3 & 39.4 \\
\hline New-Atyp & Mean & 43.7 & 29.0 & 103.9 & 129.1 & 82.6 & 3.7 & N & 38 & 35 \\
\hline$(N=72)$ & SD & 11.0 & 6.2 & 17.7 & 14.2 & 9.1 & 1.1 & $\%$ & 52.8 & 48.6 \\
\hline New-Typ & Mean & 45.6 & 32.3 & 111.3 & 134.6 & 84.6 & 4.1 & $\mathrm{~N}$ & 11 & 3 \\
\hline$(\mathrm{N}=16)$ & SD & 11.5 & 7.0 & 18.8 & 16.4 & 7.3 & 1.5 & $\%$ & 68.8 & 18.8 \\
\hline New-Com & Mean & 46.0 & 29.5 & 105.0 & 127.3 & 83.2 & 3.7 & $\mathrm{~N}$ & 40 & 32 \\
\hline$(\mathrm{N}=08)$ & SD & 12.8 & 5.7 & 15.9 & 14.5 & 9.3 & 1.3 & $\%$ & 50.0 & 40.0 \\
\hline Total CMD & Mean & 45.9 & 27.9 & 100.2 & 127.4 & 82.1 & 3.9 & $N$ & 236 & 192 \\
\hline$(N=476)$ & SD & 12.7 & 5.5 & 17.1 & 14.6 & 8.8 & 1.2 & $\%$ & 49.6 & 40.3 \\
\hline
\end{tabular}

Abbreviations: $\mathrm{BMI}=$ body mass index; $\mathrm{CGI}-\mathrm{S}$ = clinical global impression - severity scale; CMD = complete metabolic data; DBP = diastolic blood pressure; New$\mathrm{AP}=$ new antipsychotic treatment cohort; $\mathrm{SBP}=$ systolic blood pressure; $\mathrm{SD}=$ standard deviation, Waist = waist circumference 
Table 6 Pre-existing concomitant somatic diseases* at baseline (in $>5 \%$ of the patients, Prev-AP, FAS, N = 642)

\begin{tabular}{|c|c|c|c|c|c|c|c|c|c|}
\hline & & $\begin{array}{l}\text { Prev-Olz } \\
\mathrm{N}=62\end{array}$ & $\begin{array}{r}\text { Prev-Risp } \\
\mathrm{N}=67\end{array}$ & $\begin{array}{r}\text { Prev-Quet } \\
\mathrm{N}=49\end{array}$ & $\begin{array}{r}\text { Prev-Atyp } \\
\mathrm{N}=103\end{array}$ & $\begin{array}{r}\text { Prev-Typ } \\
\mathrm{N}=90\end{array}$ & $\begin{array}{r}\text { Prev-Comb } \\
\mathrm{N}=109 \\
\end{array}$ & $\begin{array}{r}\text { Prev-None } \\
\mathrm{N}=162 \\
\end{array}$ & $\begin{array}{r}\text { FAS, total } \\
\mathrm{N}=642\end{array}$ \\
\hline \multirow[t]{2}{*}{ Any } & $n$ & 23 & 20 & 15 & 36 & 36 & 45 & 46 & 221 \\
\hline & $\%$ & 37.1 & 29.9 & 30.6 & 35.0 & 40.0 & 41.7 & 28.4 & 34.5 \\
\hline \multirow[t]{2}{*}{ Hypertension } & $n$ & 17 & 12 & 5 & 18 & 18 & 19 & 18 & 107 \\
\hline & $\%$ & 27.4 & 17.9 & 10.2 & 17.5 & 20.0 & 17.6 & 11.1 & 16.7 \\
\hline \multirow[t]{2}{*}{ Lipid disorders } & $n$ & 4 & 7 & 4 & 4 & 7 & 12 & 5 & 43 \\
\hline & $\%$ & 6.5 & 10.5 & 8.2 & 3.9 & 7.8 & 11.1 & 3.1 & 6.7 \\
\hline \multirow[t]{2}{*}{ Diabetes } & $n$ & 3 & 2 & 3 & 3 & 8 & 15 & 2 & 36 \\
\hline & $\%$ & 4.8 & 3.0 & 6.1 & 2.9 & 8.9 & 13.9 & 1.2 & 5.6 \\
\hline \multirow[t]{2}{*}{ Musculoskeletal disorders } & $n$ & 1 & 4 & 2 & 4 & 6 & 9 & 8 & 34 \\
\hline & $\%$ & 1.6 & 6.0 & 4.1 & 3.9 & 6.7 & 8.3 & 4.9 & 5.3 \\
\hline
\end{tabular}

Abbreviations: FAS = full analysis set; Prev-AP = previous antipsychotic treatment

*pre-specified in data capturing form: diabetes, lipid metabolism disorder, other endocrine or metabolic disorders, liver disease, hypertension, heart and lung disease, gastrointestinal disease, urinary retention, hematological disease, thrombophilia or other coagulopathy, musculoskeletal disorders, neurological disorders, convulsions, kidney disorders, rheumatic disorder, malignant neoplasm/cancer

[1.11;2.56], $\mathrm{p}=0.015$, concomitant non-psychiatric medication OR of 3.38 [2.14;5.31], p < 0.0001).

The sex effect did not demonstrate significance in univariate logistic regression (unadjusted OR female versus male of $0.82, \mathrm{p}=0.28$ ).

An overview of factors associated with the presence of MetS is given in Table 12.

\section{Discussion}

Baseline data showed that the study population comprised patients with a wide range of age and duration of disease. As patients could be either untreated or in need of a treatment switch, this study possibly included patients who received antipsychotic medications for years, but eventually had to be switched due to treatment-emergent adverse events or insufficient efficacy.

Table 7 Concomitant non-psychiatric medication at baseline (FAS, $N=642$ )

\begin{tabular}{lc}
\hline Medication & $\mathbf{n}(\mathbf{\%})$ \\
\hline None & $502(78.44 \%)$ \\
Statins & $12(1.88 \%)$ \\
Other hypolipidemic drugs & $8(1.25 \%)$ \\
Beta-blockers & $62(9.69 \%)$ \\
Diuretics & $24(3.75 \%)$ \\
Ca-antagonists & $10(1.56 \%)$ \\
ACE-inhibitors & $32(5.00 \%)$ \\
Angiotensin-II-antagonists & $2(0.31 \%)$ \\
Other antihypertensive drugs & $22(3.44 \%)$ \\
Insulins & $9(1.41 \%)$ \\
Oral anti-diabetic drugs & $23(3.59 \%)$ \\
Oral corticosteroids & $1(0.16 \%)$ \\
Corticosteroid inhalants & $3(0.47 \%)$
\end{tabular}

Abbreviations: ACE-inhibitors = angiotensin-converting enzyme inhibitors; FAS $=$ full analysis set
The percentages of patients with known concomitant hypertension (16.7\%), lipid metabolism disorder (6.7\%) and diabetes (5.6\%) appeared moderate compared to numbers from German primary care patients (hypertension $31.6 \%$, lipid metabolism disorder $23.4 \%$, diabetes $9.4 \%$ ) [29]. However, the vital signs and laboratory data collected at baseline revealed high blood pressure in 54.8\%, increased triglycerides in $52.5 \%$ and increased blood glucose in $14.1 \%$ of the patients. This remarkable discrepancy emphasizes how important the actual monitoring of vital signs and blood values is in patients with schizophrenia, as seemingly, a large proportion of these patients were neither aware of their somatic health status nor adequately diagnosed and treated for cardiovascular risk factors.

Regarding baseline differences between the treatment groups (Prev-AP and New-AP), only two cohorts contrasted perceptibly from the others: One was the small $(\mathrm{N}=16)$ group of New-Typ. These patients had clinically noticeable high mean values for BMI $(32.3 \mathrm{~kg} /$ $\left.\mathrm{cm}^{2}\right)$, waist circumference $(111.3 \mathrm{~cm})$ and blood pressure (SBP/DBP $134.6 / 84.6 \mathrm{mmHG}$ ), and 12 of them (75\%) actually met the criteria of MetS (AHA/NHLB). Though this cohort was too small for reliable statistical evidence, a possible explanation might be that these patients were switched/newly initiated on typical antipsychotics, because their metabolic and cardiovascular risk was already evident and these substances were assumed to have a lower risk of treatment-emergent metabolic adverse events. Though, in our study, the perception of lower risk of metabolic adverse events through typical antipsychotics was not supported by the baseline values found in the Prev-Typ cohort.

The other treatment cohort with noteworthy baseline values was Prev-None. These previously untreated patients showed numerically lower mean values for BMI, blood pressure, prevalence of somatic 
Table 8 Laboratory test: patients with values out of the laboratory test reference range at baseline (Prev-AP, FAS, N = 642)

\begin{tabular}{|c|c|c|c|c|c|c|c|c|c|c|}
\hline Blood-Test & Limit* & & $\begin{array}{c}\text { Prev-Olz } \\
N=62\end{array}$ & $\begin{array}{c}\text { Prev-Risp } \\
N=67\end{array}$ & $\begin{array}{c}\text { Prev-Quet } \\
\mathrm{N}=49\end{array}$ & $\begin{array}{c}\text { Prev-Atyp } \\
\mathrm{N}=103\end{array}$ & $\begin{array}{c}\text { Prev-Typ } \\
\mathrm{N}=90\end{array}$ & $\begin{array}{c}\text { Prev-Comb } \\
\mathrm{N}=109\end{array}$ & $\begin{array}{c}\text { Prev-None } \\
\mathrm{N}=162\end{array}$ & $\begin{array}{c}\text { FAS, total } \\
\mathrm{N}=642\end{array}$ \\
\hline \multirow[t]{2}{*}{$\mathrm{HbA}_{1 \mathrm{c}}$} & $\geq 6 \%$ & $n$ & 5 & 4 & 5 & 6 & 18 & 15 & 9 & 62 \\
\hline & & $\%$ & 8.1 & 6.0 & 10.2 & 5.8 & 20.0 & 13.8 & 5.6 & 9.7 \\
\hline \multirow[t]{2}{*}{ Glucose } & $\geq 115 \mathrm{mg} / \mathrm{dL}$ & $\mathrm{n}$ & 5 & 10 & 9 & 16 & 17 & 25 & 8 & 90 \\
\hline & & $\%$ & 8.1 & 14.9 & 18.4 & 15.7 & 18.9 & 23.2 & 4.9 & 14.1 \\
\hline \multirow[t]{2}{*}{ Triglyceride } & $\geq 150 \mathrm{mg} / \mathrm{dL}$ & $n$ & 42 & 32 & 28 & 62 & 47 & 66 & 60 & 337 \\
\hline & & $\%$ & 67.7 & 47.8 & 57.1 & 60.2 & 52.2 & 60.6 & 37.0 & 52.5 \\
\hline \multirow[t]{2}{*}{ HDL-Cholesterol } & $\leq 40 \mathrm{mg} / \mathrm{dL}$ & $n$ & 9 & 9 & 10 & 12 & 10 & 12 & 11 & 73 \\
\hline & & $\%$ & 14.5 & 13.4 & 20.4 & 11.7 & 11.1 & 11.0 & 6.8 & 11.4 \\
\hline \multirow[t]{2}{*}{ C-reactive protein } & $\geq 3 \mathrm{mg} / \mathrm{L}$ & $n$ & 22 & 31 & 20 & 39 & 35 & 50 & 54 & 251 \\
\hline & & $\%$ & 35.5 & 46.3 & 40.8 & 37.9 & 38.9 & 45.9 & 33.3 & 39.1 \\
\hline
\end{tabular}

Abbreviations: $\mathrm{BMI}=$ body mass index; $\mathrm{FAS}=$ full analysis set; $\mathrm{HbA}_{1 \mathrm{c}}=$ glycated hemoglobin; $\mathrm{HDL}=$ high density lipoprotein; Prev-AP = previous antipsychotic treatment cohort

* cutoffs as specified by laboratory

concomitant disease and practically all laboratory parameters than any other Prev-AP cohort, but had a comparatively higher symptom severity at baseline (mean CGI-S 4.2).

Table 9 Prevalence of metabolic syndrome according to NCEP-ATP III and AHA/NHLB definitions by previous antipsychotic treatment at baseline, Prev-AP, FAS, N = 642

\begin{tabular}{|c|c|c|c|c|}
\hline \multicolumn{5}{|c|}{ NCEP-ATP III } \\
\hline Cohort & $\mathbf{N}$ & $\mathrm{n}$ & $\%$ & $95 \% \mathrm{Cl}$ \\
\hline Missing & & 4 & 0.6 & - \\
\hline Prev-Olz & 62 & 30 & 48.4 & 35.5 to 61.4 \\
\hline Prev-Risp & 66 & 25 & 37.9 & 26.2 to 50.7 \\
\hline Prev-Quet & 49 & 23 & 46.9 & 32.5 to 61.7 \\
\hline Prev-Atyp & 102 & 45 & 44.1 & 34.3 to 54.3 \\
\hline Prev-Typ & 90 & 38 & 42.2 & 31.9 to 53.1 \\
\hline Prev-Comb & 107 & 52 & 48.6 & 38.8 to 58.5 \\
\hline Prev-None & 162 & 34 & 21.0 & 15.0 to 28.1 \\
\hline Total & 638 & 247 & 38.7 & 34.9 to 42.6 \\
\hline \multicolumn{5}{|l|}{ AHA/NHLB } \\
\hline Cohort & $\mathrm{N}$ & $\mathrm{n}$ & $\%$ & $95 \% \mathrm{Cl}$ \\
\hline Missing & & 4 & 0.6 & - \\
\hline Prev-Olz & 62 & 30 & 48.4 & 35.5 to 61.4 \\
\hline Prev-Risp & 66 & 28 & 42.4 & 30.3 to 55.2 \\
\hline Prev-Quet & 49 & 25 & 51.0 & 36.3 to 65.6 \\
\hline Prev-Atyp & 102 & 50 & 49.0 & 39.0 to 59.1 \\
\hline Prev-Typ & 90 & 39 & 43.3 & 32.9 to 54.2 \\
\hline Prev-Comb & 107 & 61 & 57.0 & 47.1 to 66.5 \\
\hline Prev-None & 162 & 40 & 24.7 & 18.3 to 32.1 \\
\hline Total & 638 & 273 & 42.8 & 38.9 to 46.7 \\
\hline
\end{tabular}

Abbreviations: AHA/NHLB = American Heart Association/National Heart, Lung and Blood Institute

$\mathrm{Cl}=$ confidence interval, $\mathrm{FAS}=$ full analysis set; NCEP-ATP III = National Cholesterol Education Program, Adult Treatment Panel $3^{\text {rd }}$ report; Prev-AP = previous antipsychotic treatment
Apart from Prev-None, the Prev-AP cohorts did not contrast clearly with respect to baseline values; the highest percentages of patients with laboratory values out of normal range dispersed in different treatment groups for different parameters (see Table 8). This possibly reflects that changes in metabolic parameters may occur in patients treated with any antipsychotic medication, though these may differ in grade and type according to

Table 10 Prevalence rates of MetS according AHA/NHLB definition by new antipsychotic treatment, at baseline and after 3 months, (New-AP, CMD-set, $\mathbf{N}=476$ )

\begin{tabular}{ccccc}
\hline Visit 1 (Baseline) & \multicolumn{5}{c}{$\mathbf{~}$} \\
\hline Cohort & $\mathbf{N}$ & $\mathbf{n}$ & $\mathbf{9 5} \% \mathbf{C l}$ \\
\hline New-Olz & 206 & 79 & 38.4 & 31.7 to 45.4 \\
New-Risp & 69 & 24 & 34.8 & 23.7 to 47.2 \\
New-Quet & 33 & 18 & 54.6 & 36.4 to 71.9 \\
New-Atyp & 72 & 34 & 47.2 & 35.3 to 59.4 \\
New-Typ & 16 & 12 & 75.0 & 47.6 to 92.7 \\
New-Comb & 80 & 44 & 55.0 & 43.5 to 66.2 \\
CMD-total & 476 & 211 & 44.3 & 39.8 to 48.9 \\
\hline Visit 2 (month-3) & & & & \\
\hline Cohort & $\mathrm{N}$ & $\mathrm{n}$ & $\%$ & $95 \% \mathrm{Cl}$ \\
\hline New-Olz & 206 & 93 & 45.2 & 38.2 to 52.2 \\
New-Risp & 69 & 34 & 49.3 & 37.0 to 61.6 \\
New-Quet & 33 & 16 & 48.5 & 30.8 to 66.5 \\
New-Atyp & 72 & 34 & 47.2 & 35.3 to 59.4 \\
New-Typ & 16 & 11 & 68.8 & 41.3 to 89.0 \\
New-Comb & 80 & 48 & 60.0 & 48.4 to 70.8 \\
CMD-total & 476 & 236 & 49.6 & 45.0 to 54.2 \\
\hline
\end{tabular}

Abbreviations: AHA/NHLB = American Heart Association/National Heart, Lung and Blood Institute

$\mathrm{Cl}=$ confidence interval, $\mathrm{CMD}=$ complete metabolic data; MetS = metabolic syndrome; NCEP-ATP III = National Cholesterol Education Program, Adult Treatment Panel 3rd report; New-AP = new antipsychotic treatment 
Table 11 Change of metabolic syndrome components by post-baseline cohort, CMD-set, New-AP cohorts

\begin{tabular}{|c|c|c|c|c|c|c|c|c|}
\hline CMD-set & & New-Olz & New-Risp & New-Quet & New-Atyp & New-Typ & New-Com & Total \\
\hline & $\mathrm{N}$ & 206 & 69 & 33 & 72 & 16 & 80 & 476 \\
\hline \multirow[t]{3}{*}{ Waist (cm) } & Mean & 2.2 & 1.6 & -1.4 & -0.2 & -1.2 & 0.8 & 1.1 \\
\hline & SD & 7.9 & 5.8 & 3.5 & 5.3 & 4.3 & 6.0 & 6.7 \\
\hline & Median & 1.0 & 0.0 & 0.0 & 0.0 & 0.0 & 0.0 & 0.0 \\
\hline \multirow[t]{3}{*}{ Triglycerides (mkg/dL) } & Mean & -4.1 & 35.2 & 23.5 & -4.1 & -7.3 & -8.9 & 2.6 \\
\hline & SD & 115.2 & 98.1 & 137.0 & 124.1 & 78.1 & 130.7 & 118.1 \\
\hline & Median & 8.5 & 23.0 & 6.0 & 4.5 & -17.0 & -7.5 & 6.0 \\
\hline \multirow[t]{3}{*}{$\mathrm{HDL}(\mathrm{mg} / \mathrm{dL})$} & Mean & -0.1 & -1.8 & 0.6 & -0.8 & 0.5 & 0.7 & -0.3 \\
\hline & SD & 9.2 & 11.1 & 10.4 & 8.7 & 6.0 & 9.5 & 9.5 \\
\hline & Median & -1.0 & -1.0 & -2.0 & -2.0 & -0.5 & -0.5 & -1.0 \\
\hline \multirow[t]{3}{*}{ SBP $(\mathrm{mmHg})$} & Mean & 1.5 & 2.8 & -2.8 & -4.1 & 1.2 & -2.0 & $\overline{-0.1}$ \\
\hline & SD & 11.0 & 14.1 & 11.8 & 14.0 & 8.2 & 11.1 & 12.2 \\
\hline & Median & 0.0 & 0.0 & 0.0 & 0.0 & 2.0 & 0.0 & 0.0 \\
\hline \multirow[t]{3}{*}{ DBP (mmHg) } & Mean & 0.0 & 0.9 & -0.4 & -2.4 & 0.7 & -1.3 & -0.4 \\
\hline & SD & 8.1 & 9.3 & 9.9 & 9.2 & 6.4 & 8.5 & 8.6 \\
\hline & Median & 0.0 & 0.0 & 0.0 & 0.0 & 0.0 & 0.0 & 0.0 \\
\hline \multirow[t]{3}{*}{ Glucose (mg/dL) } & Mean & 0.5 & 2.6 & 3.7 & 2.1 & 0.6 & -4.4 & 0.4 \\
\hline & SD & 26.4 & 30.4 & 65.6 & 37.2 & 16.1 & 32.0 & 33.4 \\
\hline & Median & 2.0 & 0.0 & 4.0 & 1.5 & 2.0 & 0.5 & 1.0 \\
\hline \multirow[t]{3}{*}{$\overline{\mathrm{CRP}}(\mathrm{mg} / \mathrm{L})$} & Mean & 0.0 & 0.7 & 0.1 & 0.1 & -2.7 & -1.5 & -0.2 \\
\hline & SD & 4.6 & 7.3 & 1.6 & 4.8 & 10.5 & 8.9 & 6.1 \\
\hline & Median & 0.0 & 0.0 & 0.0 & -0.2 & 0.0 & 0.1 & 0.0 \\
\hline \multirow[t]{3}{*}{$\mathrm{HbA}_{1 \mathrm{c}}(\%)$} & Mean & 0.0 & -0.1 & -0.1 & 0.0 & -0.1 & 0.0 & 0.0 \\
\hline & SD & 0.3 & 0.2 & 1.0 & 0.4 & 0.3 & 0.4 & 0.4 \\
\hline & Median & -0.1 & -0.1 & 0.0 & 0.0 & -0.1 & 0.0 & 0.0 \\
\hline
\end{tabular}

Abbreviations: $\mathrm{CRP}=\mathrm{C}$-reactive protein; $\mathrm{CMD}=$ complete metabolic data; $\mathrm{DBP}=$ diastolic blood pressure; $\mathrm{Hb} \mathrm{A}_{1 \mathrm{c}}=\mathrm{glycated}$ hemoglobin, New-AP $=$ new antipsychotic treatment cohort; SBP = systolic blood pressure; SD = standard deviation, Waist = waist circumference

the properties of the respective substance and the patients' individual risk factors.

The prevalence of MetS in the FAS of $42.8 \%$ (AHA/ NHLB definition) at baseline was comparable to the findings from the CATIE study, which reported a baseline MetS prevalence of $42.7 \%$ in an US-American sample of patients with schizophrenia [28].

The Prev-AP cohorts who had received some previous antipsychotic treatment showed no statistically significant differences in MetS-rates (AHA/NHBL). However, patients who entered our study untreated (Prev-None) had a baseline MetS prevalence of $24.7 \%$, which was significantly lower than in any other cohort but Prev-Risp (42.4\%, but overlapping CI). For comparison, Moebus et al. [30] reported a MetS prevalence rate of $28.6 \pm 0.45 \%$ (AHA/NHLB criteria) in a cross-sectional sample of 33,502 primary care patients in Germany. Considering that Moebus' patients had a higher mean age than our study sample $(53.0 \pm 15.8$ years in men and $50.9 \pm 16.2$ years in women versus $43.1 \pm 13.1$ and $47.3 \pm 13.1$ years, respectively, in our study), the prevalence of MetS in the Prev-None cohort appears to resemble the rates seen in primary care patients.
Considering the changes in MetS prevalence, the differences between baseline and month-3 lacked significance for all New-AP groups. Though, looking at the mean change of the particular MetS-components, a trend to increase was apparent in lipids, which could be a possible early predictor.

The results from logistic regression models at visit 2 indicate that the factors "increased CRP", "concomitant somatic diseases", and "concomitant non-psychiatric medication" increased the odds to develop MetS, while "female sex" and "smoking" decreased them. The factors "concomitant somatic disease" and "concomitant nonpsychiatric medication" are in part comprised in the MetS definitons, and CRP is an established indicator of cardiovascular risk [31,32]. We did not expect, however, to find that smoking decreased the odds for MetS; this might possibly be an effect of the appetite reducing properties of nicotine [33].

Regarding the lower MetS-odds for women, data from the German general population [34] show women to have a lower incidence of cardiovascular and cerebrovascular events than men up to the age of 64, after which the respective rates converge (cardiovascular) or even 
Table 12 Factors associated with MetS according to NCEP-ATP III criteria, results from univariate and multivariate logistic regression, (CMD- set, $\mathrm{N}=4 \mathbf{4 7 6})$

\begin{tabular}{|c|c|c|c|}
\hline $\begin{array}{l}\text { Univariate logistic regression } \\
\text { Effect, Visit } 1\end{array}$ & Odds Ratio & $95 \% \mathrm{Cl}$ & p-Value \\
\hline Age & 1.03 & 1.02 to 1.05 & $<.0001$ \\
\hline Time since first symptoms (years) & 1.02 & 1.00 to 1.04 & 0.0399 \\
\hline Concomitant somatic disease: $\mathrm{Y}$ vs. $\mathrm{N}$ & 4.83 & 3.09 to 7.53 & $<.0001$ \\
\hline Non-psychiatric co-medication: Y vs. N & 3.38 & 2.15 to 5.31 & $<.0001$ \\
\hline Smoking status: $Y$ vs. N & 0.61 & 0.42 to 0.89 & 0.0107 \\
\hline CRP $\geq 3 \mathrm{mg} / \mathrm{L}$ vs. normal value & 1.68 & 1.11 to 2.56 & 0.0151 \\
\hline Prev-Comb vs. Prev-None & 3.56 & 1.89 to 6.70 & $<.0001$ \\
\hline Prev-Olz vs. Prev-None & 2.91 & 1.40 to 6.05 & 0.0043 \\
\hline Prev-Atyp vs. Prev-None & 3.27 & 1.72 to 6.24 & 0.0003 \\
\hline Prev-Quet vs. Prev-None & 3.74 & 1.73 to 8.09 & 0.0008 \\
\hline Prev-Risp vs. Prev-None & 2.62 & 1.27 to 5.39 & 0.0091 \\
\hline Prev-Typ vs. Prev-None & 3.07 & 1.59 to 5.91 & 0.0008 \\
\hline Effect, Visit 2 & Odds Ratio & $95 \% \mathrm{Cl}$ & p-Value \\
\hline Age & 1.02 & 1.01 to 1.04 & 0.0042 \\
\hline Time since first symptoms (years) & 1.03 & 1.01 to 1.04 & 0.0059 \\
\hline Concomitant somatic disease: Y vs. N No & 3.98 & 2.57 to 6.19 & $<.0001$ \\
\hline Non-psychiatric co-medication: Y vs. N No & 2.67 & 1.71 to 4.16 & $<.0001$ \\
\hline CRP $\geq 3$ mg/L vs. normal value & 2.36 & 1.58 to 3.51 & $<.0001$ \\
\hline Prev-Comb vs. Prev-None & 2.63 & 1.44 to 4.81 & 0.0017 \\
\hline Prev-Olz vs. Prev-None & 2.63 & 1.30 to 5.33 & 0.0071 \\
\hline Prev-Atyp vs. Prev-None & 2.07 & 1.11 to 3.85 & 0.0216 \\
\hline Prev-Quet vs. Prev-None & 2.38 & 1.13 to 5.04 & 0.0232 \\
\hline Prev-Risp vs. Prev-None & 2.16 & 1.08 to 4.33 & 0.0292 \\
\hline Prev-Typ vs. Prev-None & 2.29 & 1.22 to 4.29 & 0.0098 \\
\hline $\begin{array}{l}\text { Multivariate logistic regression } \\
\text { Effect, Visit } 1\end{array}$ & Odds Ratio & $95 \% \mathrm{Cl}$ & p-Value \\
\hline Concomitant somatic disease: $\mathrm{Y}$ vs. $\mathrm{N}$ & 4.09 & 2.37 to 7.06 & $<.0001$ \\
\hline Smoking status: Y vs. N & 0.53 & 0.32 to 0.86 & 0.0098 \\
\hline Effect, Visit 2 & Odds Ratio & $95 \% \mathrm{Cl}$ & p-Value \\
\hline CRP $\geq 3 \mathrm{mg} / \mathrm{L}$ vs. normal value & 2.00 & 1.22 to 3.30 & 0.0062 \\
\hline Non-psychiatric co-medication: Y vs. N No: & 1.98 & 0.98 to 4.04 & 0.0588 \\
\hline Concomitant somatic disease: Y vs. N No & 1.83 & 0.93 to 3.61 & 0.0796 \\
\hline Sex: female vs. male & 0.56 & 0.34 to 0.91 & 0.0185 \\
\hline Smoking status at visit 2: Y vs. $N$ & 0.60 & 0.37 to 1.00 & 0.0488 \\
\hline
\end{tabular}

Abbreviations: $\mathrm{Cl}$ = confidence interval; CMD = complete metabolic data; CRP = ; C-reactive protein; MetS = metabolic syndrome; N = No; NCEP-ATP III = National Cholesterol Education Program, Adult Treatment Panel 3rd report; New-AP = new antipsychotic treatment cohort; $\mathrm{Y}=\mathrm{Yes}$

become inverted (cerebrovascular). The review of cardiovascular risk factors in women by Evangelista and MacLaughlin [35], comprising international data published between 1990 and 2008, provided similar results. Considering the age structure of our study sample (FAS: mean age 45.2 years, Q1 36 years, Q3 54 years) our results fit well into the general picture.

They do, however, contradict the results from the CATIE study: McEvoy et al. [28] reports MetS-prevalences of $36.0 \%$ in men and $51.6 \%$ in women (fasting cohort, $\mathrm{N}=689$ ); the higher risk for MetS in women was a universal finding in all age groups, races and ethnicities. However, CATIE was a controlled clinical trial, so apart from country specific confounders as behavioral and dietary habits; possible selection bias might have impacted the results.

Several limitations of this study should be considered: As the study did not reach the required sample size, the analyses were underpowered, and therefore logistic regression models might have failed to detect all effects associated with MetS. Furthermore, the observational period of three months might have been too short to observe certain changes in metabolic status as e.g. development of insulin resistance or the processes leading 
eventually to increased CRP. Due to the observational design, treatment cohorts were defined post-hoc, depending on the actual case numbers treated with each antipsychotic, and compounds which were less frequently prescribed had to be grouped.

\section{Conclusions}

Nevertheless, the MetS-rates found in this German sample of schizophrenia patients confirm the notion that MetS-prevalence is higher in patients with schizophrenia compared to the general population, with rates increasing with the duration of illness [36]. Even though three months seemingly were too short to retrieve statistically sound evidence on all possible risk factors, we observed an early increase of triglyceride levels. Our results once more emphasize how important the controlling of the patients' metabolic situation is in schizophrenia therapy $[37,38]$ irrespective of antipsychotic medication.

\section{Acknowledgements and Funding}

We wish to thank Mrs. Catherine Beal for supporting the statistical analysis, and Mrs. Birgit Eschweiler, PhD, for drafting the methods and results sections of this manuscript.

Research was funded by Lilly Deutschland GmbH, Bad Homburg, Germany.

\section{Author details}

'Lilly Deutschland GmbH, Medical Department, 61352 Bad Homburg, Werner -Reimers-Str. 2-4, Germany. ${ }^{2}$ Institute for Clinical Research IKFE, 55116 Mainz, Parcusstr. 8, Germany. ${ }^{3}$ Kath. Marienkrankenhaus GmbH, Geriatrics Clinic, 22087 Hamburg, Alfredstr.9, Germany.

\section{Authors' contributions}

SK supported the conduct of the study and contributed to the data analysis, interpretation of data and writing of this report.

AM contributed to the data analysis, interpretation of data, and writing of this report.

$\mathrm{HPH}, \mathrm{DK}$ and TF contributed to the study design, interpretation of data, and added scientific input to this report in form of comments. All authors contributed to and have approved the final manuscript.

\section{Competing interests}

Susanne Kraemer, Anette Minarzyk, and Hans-Peter Hundemer are full-time employees of Lilly Deutschland GmbH. Thomas Forst and Daniel Kopf are members of an Eli Lilly advisory board and have received research funding from Eli Lilly.

Received: 28 April 2011 Accepted: 1 November 2011

Published: 1 November 2011

\section{References}

1. Harris EC, Barraclough B: Excess mortality of mental disorder. $\mathrm{Br} J$ Psychiatry 1998, 173:11-53.

2. Colton CW, Manderscheid RW: Congruencies in increased mortality rates, years of potential life lost, and causes of death among public mental health clients in eight states. Prev Chronic Dis 2006, 3:A42.

3. Tiihonen J, Lönnqvist J, Wahlbeck K, Klaukka T, Niskanen L, Tanskanen A, Haukka J: 11-year follow-up of mortality in patients with schizophrenia: a population-based cohort study. (FIN11 study). Lancet 2009, 374(9690):620-627.

4. Douglas IJ, Smeeth $L$ : Exposure to antipsychotics and risk of stroke: self controlled case series study. BMJ 2008, 337:a1227.

5. Brown S, Inskip H, Barraclough B: Causes of the excess mortality of schizophrenia. Br J Psychiatry 2000, 177:212-217.
6. Newcomer JW: Antipsychotic medications: metabolic and cardiovascular risk. J Clin Psychiatry 2007, 68(Suppl 4):8-13.

7. Ray WA, Chung C, Murray KT, Hall K, Stein M: Atypical antipsychitoc drugs and the risk of sudden cardiac death. N Engl J Med 2009, 360:225-235.

8. Langfeldt G: The insulin tolerance test in mental disorders. Acta Psychiatr Neurol Scand Supp/ 1952, 80:189-199.

9. Kohen D: Diabetes mellitus and schizophrenia: historical perspective. $\mathrm{Br} J$ Psychiatry 2004, 47:S64-S66.

10. Planansky $\mathrm{K}$, Heilizer F: Weight changes in relation to the characteristics of patients on chlorpromazine. J Clin Exp Psychopathol 1959, 20(1):53-57.

11. Thakore JH, Mann JN, Vlahos I, Martin A, Reznek R: Increased visceral fat distribution in drug-naive and drug-free patients with schizophrenia. Int J Obes Relat Metab Disord 2002, 26:137-141.

12. Strassnig M, Brar JS, Ganguli R: Nutritional assessment of patients with schizophrenia: a preliminary study. Schizophr Bull 2003, 29(2):393-397.

13. Bobes J, Arango C, Garcia-Garcia M, Rejas J: Healthy lifestyle habits and 10-year cardiovascular risk in schizophrenia spectrum disorders: an analysis of the impact of smoking tobacco in the CLAMORS schizophrenia cohort. Schizophr Res 2010, 119(1-3):101-109.

14. Vancampfort D, Knapen J, Probst M, van Winkel R, Deckx S, Maurissen K, Peuskens J, De Hert M: Considering a frame of reference for physical activity research related to the cardiometabolic risk profile in schizophrenia. Psychiatry Res 2010, 177(3):271-279.

15. Gianfrancesco F, White R, Wang RH, Nasrallah HA: Antipsychotic-induced type 2 diabetes: evidence from a large health plan database. J Clin Psychopharmacol 2003, 23:328-335.

16. Casey DE: Dyslipidemia and atypical antipsychotic drugs. J Clin Psych 2004, 65(Suppl 18):27-35.

17. van Winkel R, Moons T, Peerbooms O, Rutten B, Peuskens J, Claes S, van Os J, De Hert M: MTHFR genotype and differential evolution of metabolic parameters after initiation of a second generation antipsychotic: an observational study. Int Clin Psychopharmacol 2010, 25(5):270-276.

18. Grundy SM, Cleeman JI, Daniels SR, Donato KA, Eckel RH, Franklin BA, Gordon DJ, Krauss RM, Savage PJ, Smith SC Jr, Spertus JA, Costa F: Diagnosis and management of the metabolic syndrome: an American Heart Association/National Heart, Lung, and Blood Institute Scientific Statement. Circulation 2005, 112:2735-2752.

19. Expert Panel on Detection, and Treatment of High Blood Cholesterol in Adults: Executive summary of the third report of the National. Cholesterol Education Program (NCEP) expert panel on detection, evaluation, and treatment of high blood cholesterol in adults (Adult Treatment Panel III). JAMA 2001, 285:2486-2497.

20. Alberti KG, Zimmet P, Shaw J: IDF Epidemiology Task Force Consensus Group. The metabolic syndrome - a new worldwide definition. Lancet 2005, 366(9491):1059-1062.

21. Deutsche Gesellschaft für Psychiatrie, Psychotherapie und Nervenheilkunde, (ed): S3-Leitlinie Schizophrenie. Darmstadt, Germany; 2006

22. NICE (National Collaborating Centre for Mental Health, National Institute of Clinical Excellence): Schizophrenia: Core interventions in the treatment and management of Schizophrenia in primary and secondary care. Clinical Practice Guideline 82. NICE 2009 [http://www.nice.org.uk/nicemedia/ pdf/CG82FullGuideline.pdf], (accessed 26 Jan 2010).

23. Consensus Statement: Consensus Development Conference on Antipsychotic Drugs and Obesity and Diabetes. Diabetes Care 2004, 27(2):596-601.

24. Pfützner A, Forst $\mathrm{T}$ : High-sensitivity C-reactive protein as cardiovascular risk marker in patients with diabetes mellitus. Diabetes Technol Ther 2006, 8:28-36.

25. Ryan MC, Collins $P$, Thakore $J H$ : Impaired fasting glucose tolerance in firstepisode, drug-naive patients with schizophrenia. Am J Psychiatry 2003, 160:284-289.

26. Larsen ML, Høder M: Metabolic evaluation of non-insulin-dependent diabetes in primary health care - the clinical usefulness of glycated haemoglobin measurements. Scand J Prim Health Care 1989, 7(3):167-71.

27. Guy W, (ed): ECDEU Assessment Manual for Psychopharmacology. Publication ADM 76-338 Washington, DC: US Department of Health, Education and Welfare; 1976, 218-222.

28. McEvoy JP, Meyer JM, Goff DC, Nasrallah HA, Davis SM, Sullivan L, Meltzer HY, Hsiao J, Scott Stroup T, Lieberman JA: Prevalence of the metabolic syndrome in patients with schizophrenia: baseline results from the Clinical Antipsychotic Trials of Intervention Effectiveness 
(CATIE) schizophrenia trial and comparison with national estimates from NHANES III. Schizophr Res 2005, 80(1):19-32.

29. Gesundheitsberichterstattung des Bundes: Indikator 3.19 des Indikatorensatzes der GBE der Länder: Häufigste Diagnosen in Praxen von Allgemeinmedizinerinnen und -medizinern und praktischen Ärztinnen und Ärzten (in \% der Behandlungsfälle) nach Geschlecht, Rang und Anteil, Nordrhein, ab. 2002 [http://www.gbe-bund.de/gbe10/ abrechnung. prc_abr_test_logon?p_uid=gast\&p_aid = $4711 \&$ p sprache=D\&p_knoten=TR200].

30. Moebus S, Hanisch JU, Neuhäuser M, Aidelsburger P, Wasem J, Jöckel KH: Assessing the prevalence of the Metabolic Syndrome according to NCEP ATP III in Germany: feasibility and quality aspects of a two step approach in 1550 randomly selected primary health care practices. Ger Med Sci 2006, 9:4.

31. Packard RR, Libby P: Inflammation in atherosclerosis: from vascular biology to biomarker discovery and risk prediction. Clin Chem 2008, 54:24-38.

32. Torres JL, Ridker PM: Clinical use of high sensitivity C-reactive protein for the prediction of adverse cardiovascular events. Curr Opin Cardiol 2003, 18(6):471-478.

33. Perkins KA, Epstein LH, Stiller RL, Fernstrom MH, Sexton JE, Jacob RG, Solberg R: Acute effects of nicotine on hunger and caloric intake in smokers and nonsmokers. Psychopharmacology (Berl) 1991, 103(1):103-109.

34. Gesundheitsberichterstattung des Bundes: Krankheiten/Gesundheitsprobleme.[http://www.gbe-bund.de/gbe10/abrechnung. prc_abr_test_logon?p_uid=gast\&p_aid = 5813485\&p_sprache=D\&p_knoten=TR8500]

35. Evangelista $\mathrm{O}, \mathrm{Mc}$ Laughlin MA: Review of cardiovascular risk factors in women. Gend Med 2009, 6(Suppl 1):17-36

36. De Hert M, van Winkel R, Van Eyck D, Hanssens L, Wambers M, Scheen A, Peuskens J: Prevalence of diabetes, metabolic syndrome and metabolic abnormalities in schizophrenia over the course of the illness: a crosssectional study. Clin Pract Epidemol Ment Health 2006, 2:14

37. Larsen J, Holdrup M, Christensen B, Sigalin C, Nilsson PM, Kolb S: Interventions in antipsychotics-treated patients with cardiometabolic risk factors or metabolic syndrome. Eur Neuropsychopharmacol 2008, 18(Suppl 4):440-441.

38. Bobes J, Arango C, Aranda P, Carmena R, Garcia-Garcia M, Rejas J: CLAMORS Study Collaborative Group. Cardiovascular and metabolic risk in outpatients with schizophrenia treated with antipsychotics: results of the CLAMORS Study. Schizophr Res 2007, 90(1-3):162-173.

\section{Pre-publication history}

The pre-publication history for this paper can be accessed here: http://www.biomedcentral.com/1471-244X/11/173/prepub

doi:10.1186/1471-244X-11-173

Cite this article as: Kraemer et al:: Prevalence of metabolic syndrome in patients with schizophrenia, and metabolic changes after 3 months of treatment with antipsychotics - results from a German observational study. BMC Psychiatry 2011 11:173.

\section{Submit your next manuscript to BioMed Central and take full advantage of:}

- Convenient online submission

- Thorough peer review

- No space constraints or color figure charges

- Immediate publication on acceptance

- Inclusion in PubMed, CAS, Scopus and Google Scholar

- Research which is freely available for redistribution

Submit your manuscript at www.biomedcentral.com/submit
C Biomed Central 